\title{
Green Synthesis of Silver Nanoparticles Using Terminalia Bellirica Leaves Extract
}

\author{
Rashmi Rawat $^{1 *}$ - M. C. Purohit ${ }^{1} \cdot$ Mahender Singh $^{1} \bullet$ Ankit S. Bartwal $^{2}$ \\ ${ }^{1}$ Department of Chemistry, HNB Garhwal University, BGR Campus Pauri, Pauri (Garhwal) 246001, \\ Uttarakhand, India \\ ${ }^{2}$ Department of Chemistry, HNB Garhwal University, Birla campus, Srinagar Garhwal, Uttarakhand, India- \\ 246174 \\ *Corresponding Author Email: rashmirawat0892@gmail.com
}

Received: 29.8.2021; Revised: 3.9.2021; Accepted: 10.10.2021

(C)Society for Himalayan Action Research and Development

\begin{abstract}
Nowadays, for green synthesis, different parts of plant extracts are being used for the synthesis of metallic nanoparticles. Green routes for the synthesis of metallic nanoparticles are most favorable method over conventional methods. In this study, we have synthesized Ag nanoparticles from Terminalia bellirica aqueous leaves extract with $\mathrm{AgNO}_{3}$ solution. Recently, silver nanoparticles are being used for their beneficial effects on human health. It has been reported that it helps in lowering in cholesterol, blood pressure, thirst, pile, skin diseases and treatment of diabetes. Ag nanoparticles were characterized by UV-Vis spectrophotometer, XRD, TEM and FTIR techniques. It was found that $\mathrm{Ag}^{+}$ion reduced into $\mathrm{Ag}^{0}$ and showed absorption band at $447 \mathrm{~nm}$. X-Ray Diffraction for structural determination confirms the crystalline Ag nanoparticles. TEM analysis confirms the average particle size is less than $30 \mathrm{~nm}$ with spherical shape. FTIR spectra confirms the presence of active biomolecules (alcohols, phenols, proteins and nitro compounds) of plant leaves extract which played a key role in formation of $\mathrm{Ag}$ nanoparticles.
\end{abstract}

Keywords: silver nanoparticles, Terminalia bellirica, XRD, TEM, crystalline

\section{Introduction}

Terminalia bellirica Roxb is an important medicinal plant of Himalaya which belongs to Combretaceae family and is popularly known as 'bahera'. Terminalia bellirica is a deciduous tree, growing on wild throughout indian subcontinent, Srilanka and SE Asia, upto $1200 \mathrm{~m}$ in elevation (Bardul 2011; Motamarri et.al., 2012). It helps in lowering cholesterol, blood pressure, thrist, pile, skin diseases, worm, reduces ageing and in loss of appetite (Sabu et.al., 2009; Devi et.al., 2014).
The fruits pieces are baked and chewed for cough, cold, hoarseness of voice and asthma. The unripe fruits are mild laxative and ripe fruits are astringent and antidiarrheal (Motamarri et.al., 2012; Deb et.al., 2016). Oil extract from the seed pulp is used in leucoderma and alopecia. The bark is mildly diuretic and is useful in Anaemia and Leucoderma (Sabu et.al., 2009; Bardul 2011). It exhibited a variety of biological activities, such as antioxidant, antimicrobial, antidiarrheal, anticancer, analgesic, 
antipyretic, antidiabetic and antihypertensive (Elizabeth et.al; 2005; Sabu et.al., 2009; Sharma et.al., 2010; Motamarri et.al., 2012; Deb et.al., 2016). Nanoscaled materials is a material in which at least one dimension of structural component is less than $100 \mathrm{~nm}$ (Awwad et.al., 2013; Khan et.al., 2018). Metallic nanoparticles are being widely used in different fields such as medicine, agriculture, cosmetic industry, drug delivery, catalysis and waste water treatment (Thakkar et.al., 2010; Awwad et.al., 2013; Chintamani et.al., 2018; Ovais et.al., 2018). The nanosized metallic nanoparticles ( $\mathrm{Au}, \mathrm{Ag}$ and $\mathrm{Pt}$ ) are broadly being used commercially in shampoos, soaps, detergents, anti-ageing creams and perfumes for personal and beauty care (Iravani 2011; Jemel et.al., 2017). In the current scenario, the synthesis of nanoparticles in the research area is being done more biologically than chemical method because it is ecofriendly, cost effective, single step, easy to handle, safe and non-toxic (Daizy 2010; Mile et.al., 2013; Khan et.al., 2018). In biological method, microorganism (bacteria, fungi and yeast) and plant parts (leaf, bark, seeds, roots and fruits) are used for the synthesis of metallic nanoparticles $(\mathrm{Ag}, \mathrm{Au}, \mathrm{Pt}, \mathrm{ZnO}$ and CuO) (Daizy 2010; Mason et.al., 2012; Reddy et.al., 2012). Phytoconstituents (polyphenolic acid, flavones, alkaloids, tannins, terpenoids, essential oils etc) present in different plant parts extracts act as reducing, capping and stabilizing agent of metallic nanoparticles (Iravani 2011; Noruzi 2015; Sati et.al., 2020). Many research work has been reported for the synthesis of $\mathrm{Ag}$ nanoparticles using different plants and their parts (Iravani et.al., 2011; Zargar et.al., 2011). The objective of present study is to synthesize Ag nanoparticles from leaves extract of Terminalia bellirica and its characterization by XRD, UV-VIS spectrometry, TEM and FTIR analysis. This green approach is convenient, cheap, environmentally advantageous over toxic chemicals.

\section{Methodology}

\section{Preparation of aqueous plant extract}

Fresh leaves of $T$. bellirica were collected from Advani forest region, Pauri Garhwal (Uttarakhand). Leaves were washed with double distilled water to remove filth/dirt. Then, washed leaves kept for drying under shade. Dried leaves were mashed to fine powder with mortar-pestle. There after $12 \mathrm{~g}$ of mashed leaves were boiled with $250 \mathrm{~mL}$ distilled water for $20 \mathrm{~min}$ at $65^{\circ} \mathrm{C}$. Then, aqueous leaves extract was prepared after filtration with Whatman no. 1 filter paper. Extract was stored for the Ag NP's synthesis. The plant has been authenticated in the department of Botany, FRI, Dehradun.

\section{Synthesis of Ag nanoparticles}

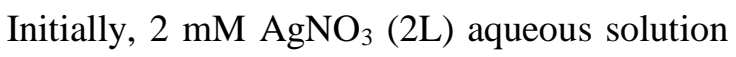
was prepared. $200 \mathrm{~mL}$ aqueous leaves extract of Terminalia Bellirica was mixed with 1800 $\mathrm{mL}$ aqueous $\mathrm{AgNO}_{3}$ solution (2mM) with 1:9 in a $2 \mathrm{~L}$ Erlenmeyer conical flask. The solution colour changed from light yellow to greyish black within 3 days indicating the formation of 
$\mathrm{Ag}$ nanoparticles. Then, solution was centrifuged for 15 minutes at 7500 RPM. There after it was washed with distilled water followed by acetone to remove impurities. The gained materials dried at $45^{\circ} \mathrm{C}$ for 1 day in oven and using mortar-pestle for grinding dried materials to get fine powdered greyish black Ag nanoparticles. Finely powdered greyish black nanoparticles were stored in air locked bottles for the characterization. Silver nitrate is obtained from Blulux Laboratories (P), Limited, Faridabad-India.

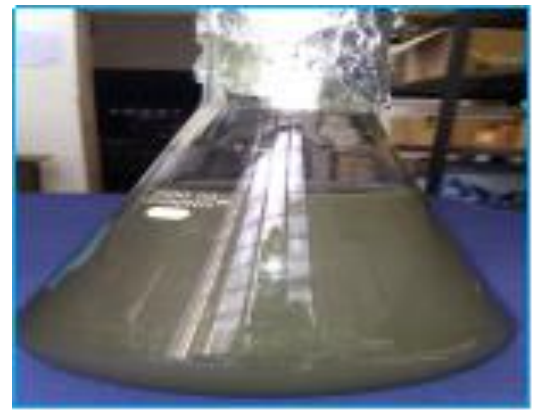

Fig .1: Synthesized Ag nanoparticles

\section{Characterization of synthesized Ag Nps}

Elite double beam UV-Vis spectrophotometer was used to investigate the formation of $\mathrm{Ag}$ nanoparticles. The spectra of the mixtures $\left(\mathrm{AgNO}_{3}\right.$ solution and leaves extract) were taken between 300 and $900 \mathrm{~nm}$.

XRD Analysis. X-ray Diffraction (XRD) (PAN Analytical, X-pert pro, Diffractometer) was used for the structural and phase determination of $\mathrm{Ag}$ nanoparticles and its spectra was taken in the range of $2 \theta$ from $0^{0}$ to $80^{\circ}$. The average particle size was calculated by using Scherrer's equation.

\section{$D=K \lambda / \beta \cos \theta$}

FTIR Analysis. FTIR spectrometer (Perkin Elmer Model RZX) was used to analyze functional groups of the synthesized $\mathrm{Ag}$ nanoparticles in the range $4000-400 \mathrm{~cm}^{-1}$ using $\mathrm{KBr}$ pellet method.

TEM Analysis. Transmission electron microscope (JEOL JEM 1400) analysis was used to determine the surface morphology of synthesized silver nanoparticles.

\section{Result and Discussion}

In the present work, aqueous leaves extract of Terminalia bellirica was used to synthesize Ag nanoparticles.

\section{UV-Visible Analysis.}

It was observed that solution color changes from light yellow to dark brown or greyish black. UV-Vis spectra of the solution was taken in the range $300-900 \mathrm{~nm}$. The color change is due to the surface plasmon resonance phenomenon in $\mathrm{Ag}$ nanoparticles (Awwad et.al., 2013). Several studies showed the similar results (Mason et.al., 2012; Jemel et.al., 2017; Sati et.al., 2020). The Surface Plasmon Resonance band observed at $447 \mathrm{~nm}$ which indicated the formation of $\mathrm{Ag}$ nanoparticles. Silver nanoparticles possesses absorption maximum band in the range of 400$500 \mathrm{~nm}$ (Kandwal et.al., 2019). (Fig. 2)

XRD Analysis. X-Ray diffraction studies confirms the crystalline nature of $\mathrm{Ag}$ nanoparticles. The XRD analysis of synthesized Ag nanoparticles from leaves extract of $T$. bellirica showed sharp diffraction peaks at $2 \Theta=36.98^{\circ}, 43.04^{\circ}$ and $63.33^{\circ}$ which are indexed to (111), (200) and (220) lattice 
planes respectively (Table 1) of face centered cubic nano crystals (Fig. 3). Comparing with the standard data, which confirm the nanocrystalline synthesized Ag nanoparticles. The average size of synthesized nanoparticles from leaves extract of T. bellirica is found to be less than $5 \mathrm{~nm}$. Similar results of synthesized Ag nanoparticles using guava leaves extract (Bose; 2016), Carob leaves extract (Awwad et.al., 2013), mulberry leaves extract (Awwad et.al., 2012) and Ocimum sanctum leaves extract (Singhal et.al., 2011; Garima et.al., 2011) were reported.

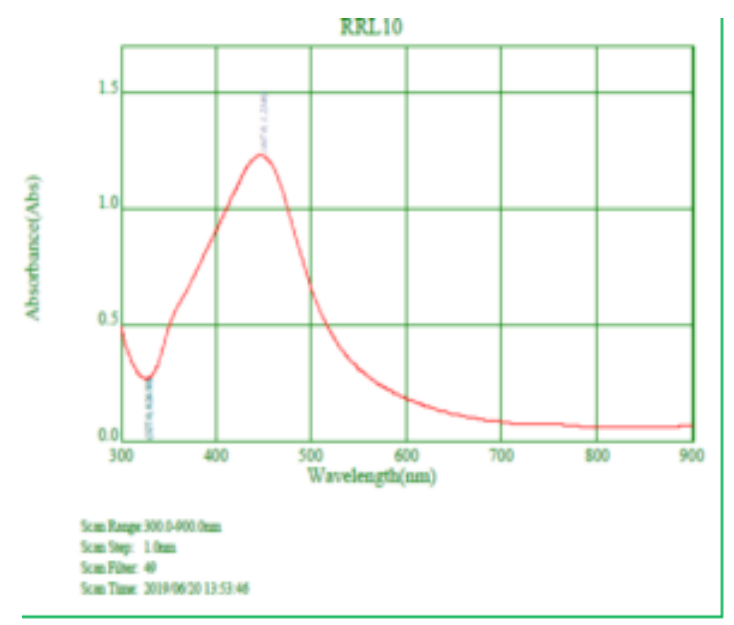

Fig. 2: UV-visible spectrum of silver nanoparticles

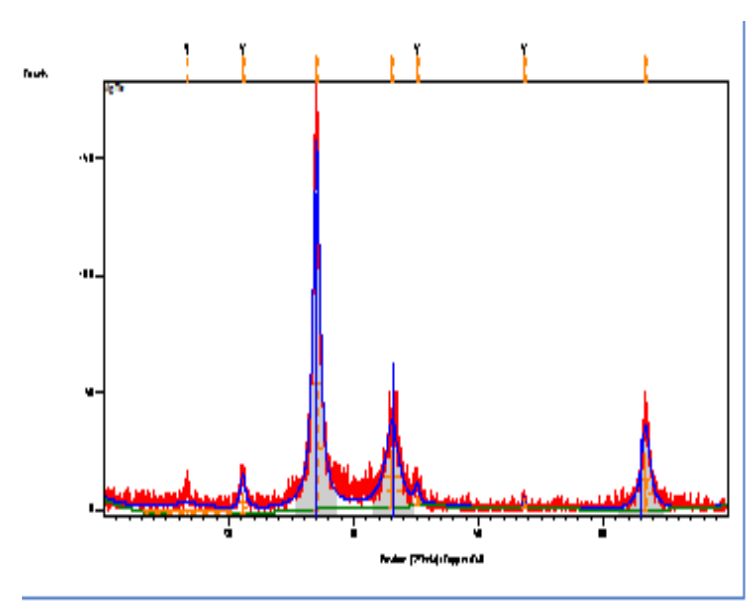

Fig. 3: XRD Spectra of silver nanoparticles
Table 1: Peak list for average size calculation of nanoparticles

$\begin{array}{ccccc}\mathbf{2 \Theta} & \text { HKL } & \begin{array}{c}\text { FWHM } \\ \text { LEFT }\end{array} & \begin{array}{c}\text { D- } \\ \text { SPACING } \\ (\AA)\end{array} & \begin{array}{c}\text { REL. } \\ \text { INT. } \\ (\%)\end{array} \\ & & & 2.42 & 100 \\ \mathbf{3 6 . 9 8} & 111 & 0.64 & 2.09 & 22.99 \\ \mathbf{4 3 . 0 4} & 200 & 1.21 & 1.46 & 23.7 \\ \mathbf{6 3 . 3 3} & 220 & 0.78 & \end{array}$

Where $\Theta$ is the Bragg's angle, FWHM is full width at half maxima, (hkl) are miller indices and d-spacing is interplanar distance.

\section{FT-IR analysis}

Green synthesized Ag nanoparticles of leaves extract of $T$. bellirica were characterized by FT-IR technique. The FT-IR spectra of $T$. bellirica leaves extract synthesized $\mathrm{Ag}$ nanoparticles in Fig. 4 shows peaks at 3429.1 $\mathrm{cm}^{-1}, 1620.2 \mathrm{~cm}^{-1}$ and $1384.2 \mathrm{~cm}^{-1}$. The absorption peaks at $3429.1 \mathrm{~cm}^{-1}$ in the FTIR spectra depicts the $\mathrm{O}-\mathrm{H}$ stretching vibration of alcohol and phenol. The peak at $1620.2 \mathrm{~cm}^{-1}$ corresponds to $\mathrm{C}-\mathrm{N}$ and $\mathrm{C}-\mathrm{C}$ stretching indicating the presence of proteins (Jemel et.al., 2017). The band at $1384.2 \mathrm{~cm}^{-1}$ corresponds to $\mathrm{N}=\mathrm{O}$ symmetry stretching of the nitro compound which may reveals that it acts as reducing and capping agents for the synthesis of silver nanoparticles. 


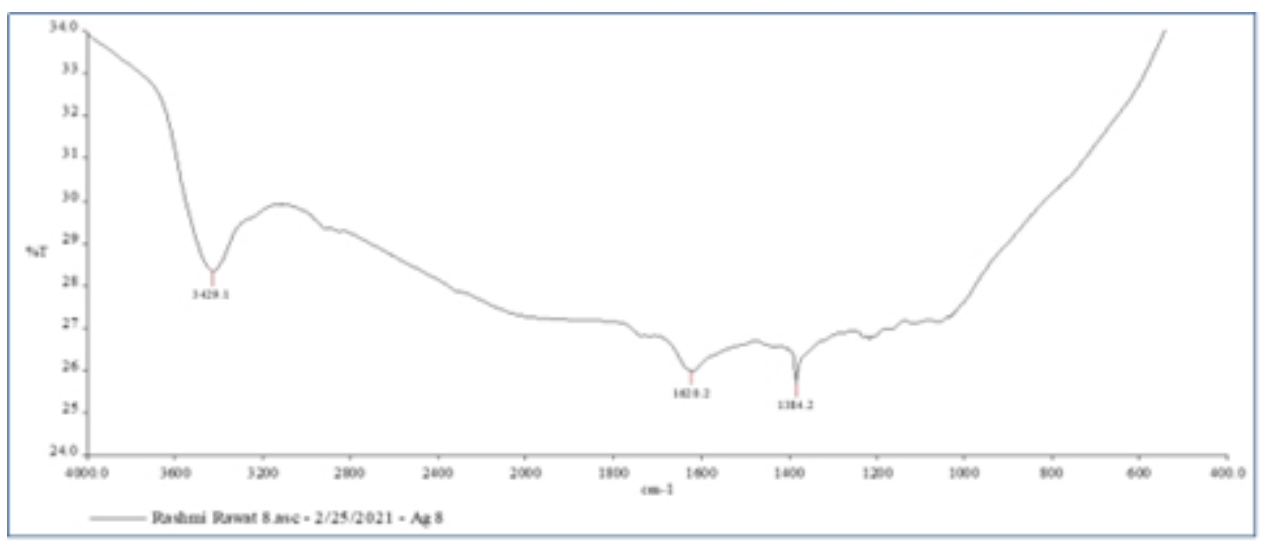

Fig. 4: FTIR spectrum of silver nanoparticles

\section{TEM analysis}

TEM analysis was used to study the surface morphology of Ag nanoparticles (Fig. 5). These results confirmed that silver nanoparticles were spherical in shape with their average size less than $30 \mathrm{~nm}$. Similar results in the synthesis of $\mathrm{Ag}$ nanoparticles using guava leaves extract (Bose; 2016), Carob leaves extract (Awwad et.al., 2013), mulberry leaves extract (Awwad et.al., 2012), and Ocimum sanctum leaves extract (Singhal et.al., 2011; Garima et.al., 2011) were reported.

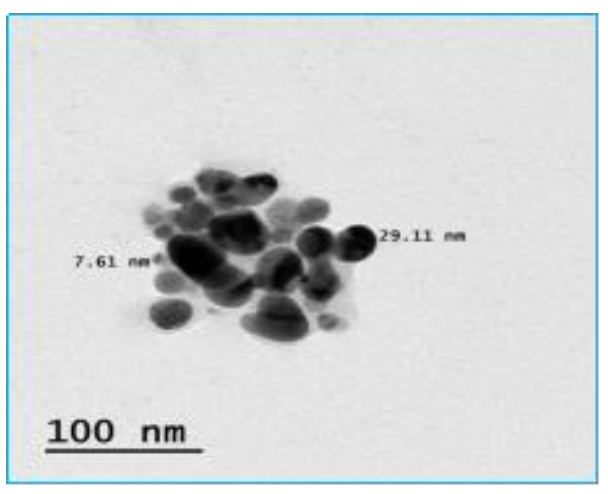

Fig. 5: Transmission electron micro-image of silver nanoparticles

\section{Conclusion}

In this study, we synthesized green $\mathrm{Ag}$ nanoparticles using leaves extract of $T$. bellirica. Characterization techniques (XRD, FTIR, TEM) confirmed that the $\mathrm{Ag}$ nanoparticles are stable, crystalline in nature, spherical in shape and crystallite size is less than $30 \mathrm{~nm}$. This green route of $\mathrm{Ag}$ nanoparticles is simple, cost effective, safe to handle and advantageous to the environment over hazardous chemicals.

\section{Acknowledgements}

Authors are thankful to USIC, HNB Garhwal University for providing XRD, Panjab University, Chandigarh for FTIR and CDRI Lucknow for TEM.

\section{Conflict of Interest}

The authors declare that there is no conflict of interests regarding the publication of this article.

\section{References}

Awwad MA, Salem NM \& Abdeen AO (2013). Green synthesis of silver nanoparticles using carob leaf extract and its antibacterial activity; International 
journal of Industrial Chemistry; 4(29):16.

Awwad AM \& Salem NM (2012). Green synthesis of silver nanoparticles by mulberry leaves extract; Nanoscience Nanotechnology; 2: 125-128.

Bardul Alam (2011). Antioxidant, Antimicrobial and Toxicity studies of the different fractions of Fruits of Terminalia bellirica Roxb; Global Journal of Pharmacology; 5(1): 07-17.

Bartwal AS, Sumit \& Sati SC (2020). Biosynthesis of silver nanoparticles from flowers of Rhododenderon campanulatum tree of Tungnath Himalaya; Applied Innovative research; 2(1): 39-43.

Bose D (2016). Biogenic synthesis of silver nanoparticles using guava (Psidium gujava) leaf extract and its antibacterial activity against Pseudomonas aeruginosa; Applied Nanoscience; 6(6): 895-901.

Chintamani RB, Salunkhe KS \& Chavan MJ (2018). Emerging use of green synthesis silver nanoparticle: an updated review; International Journal of Pharmaceutical Sciences and Research; 9(10): 4029-4055.

Daizy P (2010). Green synthesis of gold and silver nanoparticles using Hibiscus rosa sinensis; Physica E:low dimentional systems and nanostructures; 42(5): 14171424.

Deb A, Barua S \& Das B (2016). Pharmacological activities of Baheda
(Terminalia Bellerica): A review;

Journal of Pharmacognosy and Phytochemistry; 5(1): 194-197.

Devi PN, Kaleeswari S \& Poonkothai M (2014). Antimicrobial activity and phytochemical analysis of fruit extracts of Terminalia bellirica; International Journal of Pharmacy and Pharmaceutical Sciences; 6(5): 639-642.

Elizabeth KM (2005). Anti-microbial Activity of Terminalia belerica; Indian Journal of Clinical Biochemistry; 20(2): 150-153.

Garima S, Bhavesh R, Kasariya KR, Sharma AR \& Singh RP (2011). Biosynthesis of Silver Nanoparticles using Osimum sanctum (Tulsi) Leaf extract and Screening its antimicrobial activity;

Journal of Nanoparticles Research; 13:2981-2988.

Iravani S (2011). Green synthesis of metal nanoparticles using plants; Green Chemistry; 13(10): 2638-2650.

Jemel K, Sandeep BV \& Pola S (2017). Synthesis, Characterization and Evaluation of the Antibacterial Activity of Allophylus serratus Leaf and Leaf Derived Callus extracts Mediated silver nanoparticles; Journal of nanomaterials.

Kandwal A, Purohit MC, Khajuria AK \& Joshi RK (2019). Green synthesis, characterization and antimicrobial activity of silver nanoparticles using leaf extract of Ajuga Parviflora Benth. In wall; Plant Archives; 19(2): 762-768.

Khan MZH, Tareq FK, Hossen MA \& Roki MNAM (2018). Green Synthesis and 
characterization of Silver nanoparticles using Coriandrum Sativum leaf extract; Journal of Engineering Science and Technology; 13: 158-166.

Mile R, Samsudin MW \& Din LB (2013). A review on biosynthesis of nanoparticles using plant extract: An emerging green nanotechnology; Advanced Materials Research; 667: 251-254.

Mason C, Vivekanandhan S, Misra M \& Mohanty AK (2012). Switchgrass (Panicum virgatum) Extract

Mediated Green Synthesis of Silver Nanoparticles; World Journal of Nano Science and Engineering; 2: 47-52.

Motamarri NS, Karthikeyan M, Kannan M \& Rajasekar S (2012). Terminalia bellirica. Roxb- A Phytopharmacological Review; International Journal of Research in Pharmaceutical and Biomedical Sciences; 3(1): 96-99.

Noruzi M (2015). Biosynthesis of gold nanoparticles using plant extracts; Bioprocess and biosystems engineering; 38(1): 1-14.

Ovais M, Khalil AT, Ayaz M, Ahmad I, Nethi SK \& Mukharjee S (2018). Biosynthesis of Metal Nanoparticles via Microbial Enzymes: A mechanistic enzyme; Internatinal Journal of Molecular Science; 19: 4100.

Reddy GAK, Joy JM, Mitra T, Shabnam S \& Shilpa T (2012). Nano Silver: a review; International Journal of Advanced Pharmaceutics; 2(1): 9-15.
Sabu MC \& Kuttan R (2009). Antidiabetic and Antioxidant activity of Terminalia belliricaRoxb; Indian Journal of Experimental Biology; 47: 270-275.

Sati SC, Kour G, Bartwal, AS \& Sati MD (2020). Biosynthesis of Metal Nanoparticles from Leaves of Ficus palmata and Evaluation of Their Antiinflammatory and Anti-diabetic Activities; Biochemistry; 59(33): 30193025 .

Sharma SU, Sharma US, Singh A, Sutar N \& Singh PJ (2010). Screening of Terminalia bellirica Fruits Extracts for its Analgesic and Antipyretic Activities; Jordan Journal of Biological Sciences; 3(3): 121-4.

Singhal G, Bhavesh R, Kasariya K, Sharma AR \& Singh RP (2011). Biosynthesis of silver nanoparticles using Ocimum sanctum (tulsi) leaf extract and screening its antimicrobial activity; Journal of Nanoparticle Research; 13(7): 29812988.

Zargar M, Shameli K, Najafi GR \& Farahani F (2014). Plant mediated green biosynthesis of silver nanoparticles using Vitex negundo L. Extract; Journal of Industrial and Engineering Chemistry; 20(6): 4169-4175 